\title{
Evaluating effects of providing hay on behavioral development and performance of group-housed dairy calves
}

\section{K. C. Horvath and E. K. Miller-Cushon*}

Department of Animal Sciences, University of Florida, Gainesville 32611

\section{ABSTRACT}

Providing access to forage has been shown to influence feeding behavior and non-nutritive oral behavior in individually housed calves, and these effects may be enhanced or altered in calves reared in social housing. We evaluated the effect of hay provision on the behavioral development and performance of group-housed dairy calves. Holstein calves $(\mathrm{n}=32)$ were grouphoused (4 calves per group) at $17 \pm 3$ (mean \pm SD) d of age. All calves were provided milk replacer $(8 \mathrm{~L} / \mathrm{d})$ via an automated milk feeder and pelleted starter and water ad libitum. Pens were randomly assigned to receive either chopped coastal Bermuda grass in buckets adjacent to the starter trough (starter and hay, STH; n $=4$ pens), or no additional feed (starter only, ST; $\mathrm{n}=$ 4 pens). Calves were weaned through a 10-d stepdown program beginning at $46 \mathrm{~d}$ of age. Intake of solid feed and hay were recorded daily, and body weights were measured weekly. The behavior of 2 focal calves per pen was recorded continuously from video for $12 \mathrm{~h}$ on 2 consecutive days during each of wk 4, 6, and 7 of life, to measure solid feed intake time, grooming, and pendirected sucking. Hay provision influenced total feed intake, with calves provided hay having greater total solid feed intake in the week before weaning ( 0.79 vs. 0.55 $\mathrm{kg} / \mathrm{d}$, STH vs. ST, respectively; $\mathrm{SE}=0.19)$. Average daily gain (ADG) was similar during the pre-weaning period but tended to be greater for STH calves during weaning. Calves in pens provided hay also had fewer unrewarded visits to the milk feeder during weaning (12.5 vs. 21.1 visits per $12 \mathrm{~h}$, STH vs. ST, respectively; $\mathrm{SE}=3.59)$ and performed less pen-directed sucking (9.11 vs. 19.3 min per 12 h, STH vs. ST, respectively; $\mathrm{SE}=2.86)$. Self-grooming time and bout characteristics evolved differently between treatments over time, with pens of calves provided hay having a greater increase in frequency and duration of self-grooming bouts during weaning. Overall, we found that providing hay to pre-

Received February 22, 2019.

Accepted June 29, 2019.

*Corresponding author: emillerc@ufl.edu weaned calves resulted in behavioral and performance benefits, including greater total feed intake and reductions in pen-directed sucking, suggesting that access to hay may improve calf welfare.

Key words: dairy calf, group housing, feeding behavior, hay, grooming

\section{INTRODUCTION}

Evidence suggests that providing dairy calves access to hay, in addition to milk and starter during the pre-weaning period, may have both performance and behavioral benefits. From a performance standpoint, provision of hay may stimulate greater solid feed intake before weaning (Khan et al., 2011; Castells et al., 2012), but effects of forage provision depend on different factors, including variety of forage and form of starter. For example, calves prefer hay over straw (Webb et al., 2014) and demonstrate higher intakes of grass hays compared with straw and silage (Castells et al., 2012). It has also been suggested that provision of forage may be most beneficial from a rumen development standpoint when the starter is pelleted, rather than texturized (Suarez-Mena et al., 2016). Providing hay has been found to improve rumen environment and rumen development (Khan et al., 2011; Castells et al., 2013; Pazoki et al., 2017), and some studies suggest that hay intake may improve feed efficiency and growth (Coverdale et al., 2004; Castells et al., 2012), whereas others report similar growth with provision of forage (Ueno et al., 2014).

In naturalistic conditions, calves consume forage early in life. Extensively reared beef calves begin grazing slowly in the first weeks of life, with patterns of activity mirroring adult cows (Nicol and Sharafeldin, 1975), suggesting that early foraging is part of the natural development of calf feeding behavior and is socially facilitated. Allowing for this component of feeding behavior by providing hay in early life may be broadly beneficial for behavioral development of calves. Importantly from a behavioral standpoint, calves consistently select a proportion of hay in their diet (Phillips, 2004; Castells et al., 2012), even sorting within mixed diets for the 
hay fraction (Miller-Cushon et al., 2013a; Costa et al., 2016), suggesting that they are motivated to consume forage. Increased opportunities for foraging, as facilitated by hay provision, reduce pen-directed sucking in individually housed calves (Haley et al., 1998; Horvath and Miller-Cushon, 2017) and increase rumination and decrease tongue playing in older veal calves (Webb et al., 2015). Non-nutritive oral behaviors typically occur as a redirection of natural sucking behavior (Jensen and Weary, 2013) and may be directed toward other calves in group-housed settings (Lidfors, 1993). Calves perform less non-nutritive sucking when provided higher milk allowances (Jung and Lidfors, 2001) and access to a teat (de Passillé, 2001; Lupoli et al., 2001), yet reductions in non-nutritive oral behavior seen with forage provision suggest that access to hay may satisfy a motivation for oral manipulation that might otherwise be redirected toward pen fixtures or pen mates. In previous work, we found increased behavioral flexibility in calves provided hay and milk via a teat, instead of by bucket (Horvath and Miller-Cushon, 2018), suggesting that providing outlets for highly motivated oral behaviors is beneficial for behavioral development. Evidence also suggests possible links between grooming and the motivation to perform oral behaviors, including social grooming or sucking, as cattle will display mouth movements similar to those seen in tongue rolling when brushed (Simonsen, 1994). However, possible effects of hay provision on grooming and social behaviors have not been explored.

Despite evidence that social housing influences feeding behavior of dairy calves, the effects of hay provision on the behavioral development of group-housed dairy calves has not been well studied over the pre-weaning period. Social contact influences behavioral development by providing opportunities for social learning and socially facilitating behavior, which influences acquisition and performance of feeding behaviors and acceptance of novel foods across species (reviewed by Galef and Giraldeau, 2001). For example, housing calves in pairs has been found to provide performance benefits, including stimulating solid feed intake and improving weight gain, particularly during weaning (Costa et al., 2015; Miller-Cushon and DeVries, 2016). Further, Phillips (2004) found that group-housed calves consumed more fresh-cut grass than did calves housed individually, and Costa et al. (2014) describe reduced food neophobia in calves reared in social groups with access to adult cows. This evidence of social influences on acceptance of solid feed in calves suggests that effects of hay provision on performance and behavior might be expected to be enhanced in group-housed calves compared with calves housed individually. Therefore, our objective was to examine the effects of hay provision on the development of feeding patterns, non-nutritive oral behaviors, social behaviors, and performance of group-housed calves throughout the pre-weaning stage and across the weaning transition. We hypothesized that, in addition to previously reported benefits of hay provision in stimulating solid feed intake, access to hay would reduce non-nutritive oral behaviors, including cross-sucking, in group-housed calves and would promote grooming and social behaviors.

\section{MATERIALS AND METHODS}

\section{Animals and Management}

Thirty-two Holstein heifer and bull calves $(\mathrm{n}=32$; 16 heifers and 16 bulls) were enrolled at the University of Florida Dairy Unit (Hague, FL). Calves were managed according to the standard operating procedures for this facility, with all study procedures reviewed and approved by the University of Florida Institutional Animal Care and Use Committee. This experiment was conducted in the fall (September to November; average temperature $21.7^{\circ} \mathrm{C}$, with average daily maximum $26.5^{\circ} \mathrm{C}$ ). Calves received $4 \mathrm{~L}$ of quality-controlled colostrum by bottle within $1 \mathrm{~h}$ of birth and were uniquely identified using radiofrequency identification ear tags. From birth, calves were initially housed in individual wire pens, allowing visual but not physical contact, and provided $8 \mathrm{~L} / \mathrm{d}$ of pasteurized waste milk via teat buckets in 2 daily feedings.

At approximately 2 wk of age (17 $\pm 3 \mathrm{~d}$ of age; mean $\pm \mathrm{SD}$ ), calves were moved to group pens (4 calves per pen; 2 heifers and 2 bulls per pen; pen dimensions 3.7 $\times 8.0 \mathrm{~m}$ ) deep-bedded with sand and located under an open-sided barn equipped with overhead fans to circulate air. All calves in each group were enrolled on the same day. All pens had ad libitum access to water and pelleted calf starter $(22 \% \mathrm{CP}$ and $2 \%$ fat; AmpliCalf Starter Warm Weather, Purina Animal Nutrition LLC, Shoreview, MN; Table 1) via a feeding trough (10

Table 1. Chemical composition of feeds (mean \pm SD; DM basis)

\begin{tabular}{lcr}
\hline Chemical composition $^{1}$ & Starter $^{2}$ & \multicolumn{1}{c}{ Hay $^{3}$} \\
\hline DM (\%) & $93.13 \pm 2.34$ & $94.02 \pm 0.53$ \\
CP (\% of DM) & $22.17 \pm 0.40$ & $11.03 \pm 0.84$ \\
ADF (\% of DM) & $14.83 \pm 0.57$ & $42.70 \pm 1.80$ \\
NDF (\% of DM) & $25.43 \pm 1.21$ & $74.42 \pm 1.96$ \\
NFC (\% of DM) & $44.80 \pm 1.32$ & $9.27 \pm 2.47$ \\
TDN (\% of DM) & - & $44.80 \pm 1.09$ \\
\hline
\end{tabular}

${ }^{1}$ Values were obtained from chemical analysis of feed samples.

${ }^{2}$ Pelleted, Ampli-Calf Starter 20 Warm Weather; Purina Animal Nutrition LLC, Shoreview, MN.

${ }^{3}$ Chopped coastal Bermuda grass $(5 \mathrm{~cm})$. 
cm deep $\times 20 \mathrm{~cm}$ wide $\times 152 \mathrm{~cm}$ long). Starter was replaced daily.

Upon introduction the group pen, all calves received a maximum of $8 \mathrm{~L} / \mathrm{d}$ of milk replacer $(28 \% \mathrm{CP}$ and $15 \%$ fat, with Bovatec and Clarifly; Southeast Milk Inc., Mayo, FL) fed through an automated milk feeder (CF1000X, DeLaval, Kansas City, MO). The feeder was set to limit milk intake per visit to a maximum of 2.5 L. Calves were weaned over $10 \mathrm{~d}$, beginning at $47 \pm 3$ $\mathrm{d}$ of age, using an incremental stepdown program (8 to $2 \mathrm{~L} / \mathrm{d})$.

Calves received a weekly veterinary exam and were monitored daily for signs of illness by farm personnel. Before movement to group pens ( $<2$ wk of age), it was common for calves to experience mild diarrhea, which was treated with provision of electrolytes. Only calves that were clinically healthy at the point of entry to group housing were enrolled in the study. Calves were determined to be healthy for the duration of the experiment, based on daily health checks by study staff and weekly clinical exams.

\section{Experimental Design}

Upon introduction to group housing, each pen of 4 calves was randomly assigned to receive either starter with additional chopped coastal Bermuda grass hay (STH; $\mathrm{n}=4$ pens), or no additional feed (ST; $\mathrm{n}=4$ pens). Based on a power calculation (proc power; SAS version 9.4, SAS Institute Inc., Cary, NC), it was estimated that 4 pens per treatment should be sufficient to detect differences in primary response variables, with approximately $80 \%$ power, based on estimates of variance drawn from previous data collected from small groups of calves (feeding time and meal characteristics of pair-housed calves; Miller-Cushon and DeVries, 2016) and considering estimated effect sizes drawn from previous studies investigating effects of providing forage on feeding behavior outcomes (Castells et al., 2012; Horvath and Miller-Cushon, 2017).

The hay was chopped to pass through a 5 -cm sieve and provided in 2 buckets $(20 \mathrm{~cm}$ wide $\times 30 \mathrm{~cm}$ deep $)$ placed adjacent to the feeding trough containing the starter. Deeper buckets were provided for the hay than for the pelleted starter, to reduce spillage given the volume of the hay provided, and 2 buckets were provided (in addition to starter provided in a trough, as discussed above) to ensure availability of hay to multiple calves simultaneously. Both the starter and hay feeders were filled such that the surface of the feed was similarly near the top of the bucket and readily accessible. Hay was replenished daily and was fully replaced as needed or once per week. The amount of starter and hay provided was increased based on the amount of feed each pen consumed over time, to allow ad libitum intake (target $20 \%$ orts). Feed levels were checked in the evening, and additional feed was added as needed.

\section{Data Collection}

Daily individual milk intake and the number of rewarded and unrewarded visits to the feeder were recorded by the automated milk feeder. Daily starter and hay intake were measured at the pen level, based on the amount offered and the amount refused. Calves were weighed weekly using a floor scale (VS2000 floor scale, A and A Scales, Prospect Park, NJ), and BW was used to calculate weekly ADG. Chest circumference and withers height were also measured weekly, using a measuring tape (3.04 m; Dritz, Spartanburg, $\mathrm{SC})$ to evaluate growth.

To determine DM of the feed and assess the daily DMI at the pen level, we sampled fresh feed and individual orts from each pen weekly, just before removal and delivery of fresh feed. Samples taken for DM were oven-dried within $4 \mathrm{~h}$ of collection, at $55^{\circ} \mathrm{C}$ for $48 \mathrm{~h}$, to determine DM content. To determine the nutritional profiles of solid feed, samples of hay and starter were sent to Cumberland Valley Analytical Services Inc. (Waynesboro, PA) for analysis of DM (1358C; AOAC International, 2000: method 930.15), ash (5358C; AOAC International, 2000: method 942.05), ADF (AOAC International, 2000: method 973.18), NDF with heat-stable $\alpha$-amylase and sodium sulfite (Van Soest et al., 1991), and $\mathrm{CP}(\mathrm{N} \times 6.25$; AOAC International, 2000: method 990.03; Leco FP-528 Nitrogen Analyzer, Leco, St. Joseph, MI). The nutrient content of solid feed is reported in Table 1.

Behavioral data were collected during 2 observation periods to characterize behavioral development during the pre-weaning stage [wk 4 (29 to $30 \pm 5 \mathrm{~d}$ of age) and wk 6 ( 43 to $44 \pm 3 \mathrm{~d}$ of age)] and during 1 observation period to assess behavior during weaning [wk 7 (50 to $51 \pm 4 \mathrm{~d}$ of age)]. Each pen was recorded using a digital video camera (Axis M2026-LE Network Camera; Axis Communications, Lund, Sweden) mounted approximately $3 \mathrm{~m}$ from the ground. Behaviors were recorded continuously from video using Behavioral Observation Research Interactive Software (BORIS; Friard and Gamba, 2016). For each pen, the behaviors of 2 focal animals (both heifers from each pen were selected; 2 calves per pen and 8 calves per treatment) were recorded from 0600 to $1800 \mathrm{~h}$ to capture daylight hours on 2 consecutive days in each observation week. As these observation days were assigned based on calf age, they were the same for focal calves within the same pen 
but differed between pens. Focal calves were identified on video by their unique coat patterns. We characterized the following behaviors: self-grooming (defined as licking or mouth movement in contact with any part of own body or scratching the back of head with the foot), allogrooming (defined as licking or mouth movement in contact with any part of another calf's body or head), eating starter (defined as head lowered with mouth in starter trough), eating hay (defined as head lowered with mouth in hay bucket), displacements from feeder (defined as contact from another calf resulting in the focal calf backing out of the automated milk feeder stall), waiting to use feeder (defined as calf standing within 1 body length of automated milk feeder stall with head directed to the stall while another calf occupies the stall space), pen-directed sucking (defined as mouth open and in contact with parts of pen sides or fixtures), cross-sucking (defined as calf sucking the ear, scrotum, prepuce, tail, udder area, or navel of another calf; Lidfors, 1993), and social lying (defined as lying down with another calf lying within 1 body length). A total of 4 observers were used to characterize these behaviors from video (interobserver reliability was calculated for 1 day of video collection, with Cohen's kappa $\geq 0.85$, as calculated in BORIS, for all observer comparisons).

\section{Behavioral Bout Analysis}

We analyzed data to determine bout characteristics for solid feed intake time, grooming, and pen-directed sucking. The bout analysis was performed for data pooled by treatment (across all days), according to methods described previously (Horvath and MillerCushon, 2019). Grooming behavior data from calves on the control treatment only were previously included in calculations performed by Horvath and Miller-Cushon (2019) to validate and describe methods for calculating grooming bout criteria. Briefly, we took the $\log 10$ frequency distribution of the interval lengths between durations of time that each individual was performing each behavior (combined feeding time, hay feeding time, starter feeding time, pen-directed sucking, self-grooming, and allogrooming), over each day of observation. Bout criteria were calculated by fitting a mixture of normal distributions to the distributions of $\log 10$-transformed intervals using the method of exact maximum likelihood (using the $\mathrm{R}$ package mixdist; Macdonald and Du, 2018). A mixture of 2 normal distributions was fit to the data. These 2 distributions were interpreted as frequency distributions of pauses within bouts and between bouts. Based on conditional probabilities generated within the mixdist package, the bout criterion was determined as the point at which the distribution curve corresponding to the shorter intervals intersected the distribution curve corresponding to the longer intervals. Three normal distributions provided the best fit for modeling self-grooming data, and bout characteristics were determined based on the bout criterion corresponding to the intersection between the first and second distribution curve. The bout criteria for all feeding time (combined starter and hay feeding time for STH calves, and starter only for ST calves) was determined as $158.5 \mathrm{~s}$ for both treatments. For STH calves, bout criteria were determined as $63.1 \mathrm{~s}$ for starter feeding time and $39.8 \mathrm{~s}$ for hay feeding. Bout criteria for other behaviors were determined as $125.9 \mathrm{~s}$ for allogrooming, 63.1 s for pen-directed sucking, and $50.1 \mathrm{~s}$ for self-grooming bouts.

Bout characteristics were calculated based on bout criteria as day-level bout frequency (counted as the number of intervals between periods of observed behavior that exceeded the criterion), total daily bout time (sum of duration performing the behavior and intervals shorter than the bout criterion), and bout duration (bout time divided by bout frequency).

\section{Statistical Analysis}

Data were screened for normality before analysis using the PROC UNIVARIATE of SAS (version 9.4; SAS Institute Inc.). All data collected daily (total DMI, hay DMI, and starter DMI) were summarized by pen and week during the milk-feeding stage (wk 2 through wk 6 ) and by day during the 10-d weaning period. All data collected weekly (growth and ADG) were summarized by pen and week during the milk-feeding stage and only by pen during weaning, because measures were only collected once during this period. Once summarized, these data (pen-level DMI, ADG, and growth measurements) were analyzed separately by stage (pre-weaning or weaning) using the MIXED procedure of SAS, with week or day, as described above, included for a repeated measures data. The model included the fixed effects of treatment, time (week or day), and treatment $\times$ time interaction, with the pen as the subject. For analysis of ADG, average pen-level birthweight was included in the model as a covariate. The variance-covariance matrix structure (autoregressive or Toeplitz) was selected for each measure based on the best fit according to Schwarz's Bayesian information criterion.

Behavioral data (including total duration, bout frequency, and bout duration of feeding patterns, pendirected sucking, self-grooming, and allogrooming, and duration of social lying) were summarized by pen and observation week (wk 4, 6, or 7) and analyzed in a 
general linear mixed model using the MIXED procedure of SAS, with week as a repeated measure. The model included the fixed effect of treatment, week, and treatment $\times$ week interaction and the random effect of pen. We selected the autoregressive variance-covariance matrix structure for the weekly behavioral data.

Diurnal patterns of feeding (total feeding time, hay feeding time, and starter feeding time) were calculated as hourly totals of feeding behavior and were summarized and analyzed separately by week. Effects of treatment on diurnal feeding patterns (time spent consuming starter and total time spent consuming feed) were analyzed in a model similar to the one described above, with hour as a repeated measure and compound symmetry selected as the best fit variance-covariance matrix structure. For pens provided hay, diurnal patterns of hay and starter feeding time were compared in a model including the fixed effects of feed type, hour, and hour $\times$ feed type interaction.

All values reported are least squares means. Significance was declared at $P<0.05$, and trends were reported if $0.05 \leq P \leq 0.10$.

\section{RESULTS}

Milk intake (7.24 vs. $7.37 \mathrm{~L} /$ calf per day, ST vs. STH pens; $\mathrm{SE}=0.22 ; P=0.68)$ and the frequency of rewarded visits (6.50 vs. 6.28 visits/calf per day, ST vs. $\mathrm{STH} ; \mathrm{SE}=1.00 ; P=0.88)$ and unrewarded visits $(4.59$ vs. 6.34 visits/calf per day, $\mathrm{ST}$ vs. $\mathrm{STH} ; \mathrm{SE}=1.22 ; P$ $=0.35)$ were similar between treatments during the pre-weaning stage. During weaning, milk intake (4.76 vs. $4.73 \mathrm{~L} /$ calf per day, $\mathrm{ST}$ vs. $\mathrm{STH} ; \mathrm{SE}=0.54 ; P=$
0.96 ) and the frequency of rewarded visits (4.35 vs. 3.20 visits/calf per day, $\mathrm{ST}$ vs. STH; $\mathrm{SE}=0.96 ; P=$ 0.42 ) were similar between treatments, but ST pens tended to have more unrewarded visits to the automated milk feeder (21.1 vs. 12.5 visits/calf per day, ST vs. STH pens; $\mathrm{SE}=3.59 ; P=0.05)$. As determined from video observation in wk 4,6 , and 7 , the number of displacements from the milk feeder (0.44 vs. 0.73 displacements/calf per $12 \mathrm{~h}, \mathrm{ST}$ vs. STH; SE $=0.15$; $P=0.23)$ and time spent waiting to access the feeder (144.24 vs. 183.34 s per 12 h, ST vs. STH; $\mathrm{SE}=37.78$; $P=0.49)$ were similar between treatments and over time $(P>0.60)$.

Pens offered hay consumed it at an average rate of $15 \%$ of total DMI during the pre-weaning period (Table 2) and increased intake over time (Figure 1a). Provision of hay influenced total feed intake during the pre-weaning stage (Table 2): starter DMI was similar between treatments, but total DMI was subject to a treatment $\times$ week interaction, with calves in pens provided hay tending to increase their total intake to a greater extent over time (intake in wk 6: 0.79 vs. $0.55 \mathrm{~kg} /$ calf per day, STH vs. ST pens; $\mathrm{SE}=0.19 ; P=0.05$; Figure 1b). Total feed intake did not differ between treatments during weaning. Weight gain and growth were similar through the pre-weaning stage, but STH pens tended to have greater ADG during weaning (Table 2).

When considering the total time spent feeding (combined hay and starter feeding time for STH pens), provision of hay resulted in more time spent feeding and more frequent, longer meals (Table 3 ), despite the same meal criteria applied to both treatments. Meal frequency and duration increased over time, across

Table 2. Feed intake, ADG, and growth of calves provided starter without (ST; $\mathrm{n}=4$ pens) or with access to hay $\left(\mathrm{STH} ; \mathrm{n}=4\right.$ pens) during pre-weaning (wk 3-6) and weaning (10-d milk stepdown) ${ }^{1}$

\begin{tabular}{|c|c|c|c|c|c|c|}
\hline \multirow[b]{2}{*}{ Item } & \multicolumn{2}{|c|}{ Treatment $(\mathrm{T})$} & \multirow[b]{2}{*}{ SE } & \multicolumn{3}{|c|}{$P$-value } \\
\hline & $\mathrm{ST}$ & $\mathrm{STH}$ & & $\mathrm{T}$ & Wk & $\mathrm{T} \times \mathrm{wk}$ \\
\hline \multicolumn{7}{|l|}{ Pre-weaning $^{2}$} \\
\hline Total DMI $(\mathrm{kg} / \mathrm{d})$ & 0.55 & 0.79 & 0.19 & 0.41 & $<0.01$ & 0.04 \\
\hline Starter DMI $(\mathrm{kg} / \mathrm{d})$ & 0.55 & 0.68 & 0.17 & 0.59 & $<0.01$ & 0.12 \\
\hline Hay DMI (kg/d) & - & 0.12 & 0.03 & - & $<0.01$ & - \\
\hline $\mathrm{ADG}(\mathrm{kg} / \mathrm{d})$ & 0.84 & 0.77 & 0.04 & 0.29 & 0.17 & 0.87 \\
\hline Withers height $(\mathrm{m})$ & 0.88 & 0.87 & 0.007 & 0.35 & 0.004 & 0.42 \\
\hline Chest circumference (m) & 0.89 & 0.88 & 0.01 & 0.63 & 0.001 & 0.39 \\
\hline \multicolumn{7}{|l|}{ Weaning } \\
\hline Total DMI (kg/d) & 3.03 & 3.35 & 0.31 & 0.49 & - & - \\
\hline Starter DMI $(\mathrm{kg} / \mathrm{d})$ & 3.03 & 3.15 & 0.29 & 0.78 & - & - \\
\hline Hay DMI (kg/d) & - & 0.29 & 0.01 & - & - & - \\
\hline $\mathrm{ADG}(\mathrm{kg} / \mathrm{d})$ & 0.57 & 0.72 & 0.06 & 0.097 & - & - \\
\hline Height $(\mathrm{m})$ & 0.88 & 0.87 & 0.007 & 0.32 & - & - \\
\hline Chest circumference $(\mathrm{m})$ & 0.95 & 0.96 & 0.01 & 0.58 & - & - \\
\hline
\end{tabular}

${ }^{1}$ All data are summarized and analyzed at the pen level.

${ }^{2}$ Data are averaged by week. 
a)

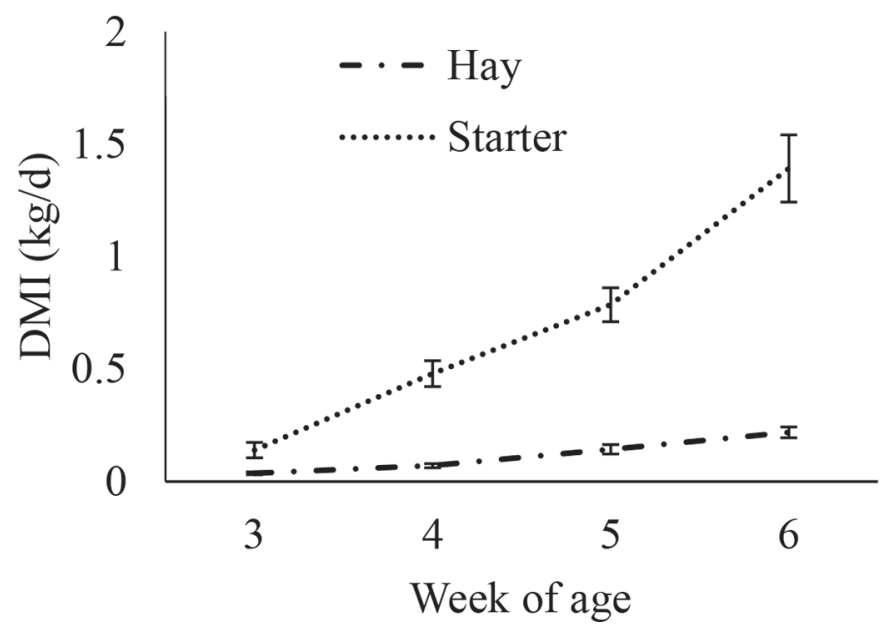

b)

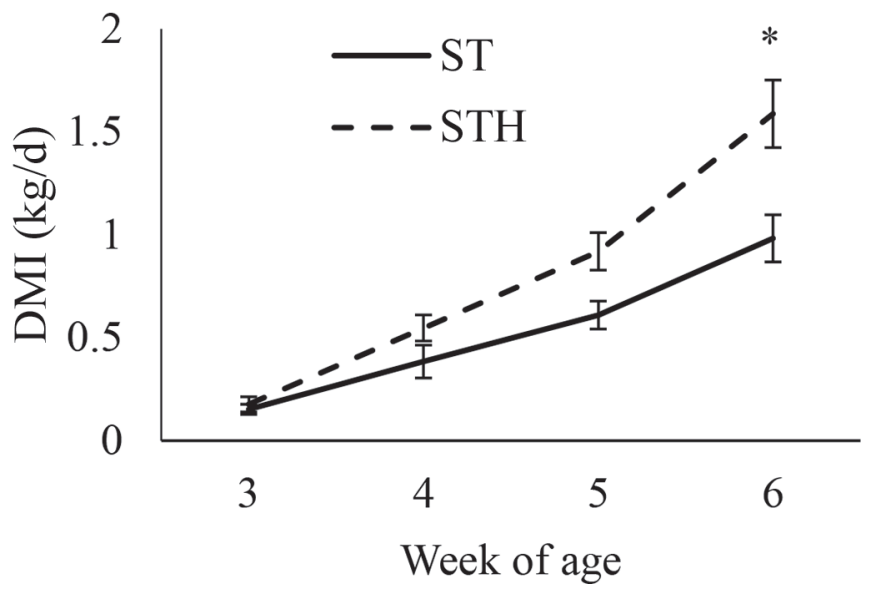

Figure 1. (a) Hay and starter DMI for test group (STH, provided combined starter and hay) calves only. (b) Total DMI for both control group (ST, provided starter only) and STH calves during the pre-weaning period. Data are summarized and analyzed at the pen level $(\mathrm{n}=4$ pens per treatment) and averaged across each week. Error bars represent SE. Asterisks $\left(^{*}\right)$ indicate significant difference $(P<0.05)$.

treatments. Provision of forage did not influence total time spent consuming starter but did influence starter meal patterning: starter meal time and meal duration tended to evolve differently between treatments over time, with meal duration for ST pens increasing to a greater extent over time compared with STH. Overall, calves in ST pens consumed their starter in less frequent, longer meals than did the calves in STH pens. Whereas starter meal frequency and duration increased over time across treatments, hay feeding patterns were more static across weeks, despite increasing intake (Figure 1a). Time spent consuming hay tended to change between weeks, decreasing in wk 6 relative to the other weeks (Table 3). Hay meal frequency and meal time increased during weaning, whereas meal duration was relatively similar between weeks (Table 3 ).

Provision of hay influenced diurnal feeding patterns. In wk 4, diurnal patterns of time spent consuming

Table 3. Description of feeding and bout characteristics of calves on different treatments (T): provided starter with hay $(\mathrm{STH} ; \mathrm{n}=4$ pens) or starter only, with no additional feed ( $\mathrm{ST} ; \mathrm{n}=4$ pens), recorded continuously over a 12-h observation period (0600 to $1800 \mathrm{~h}$ ) on 2 consecutive days in wk 4,6 , and 7 of life ${ }^{1}$

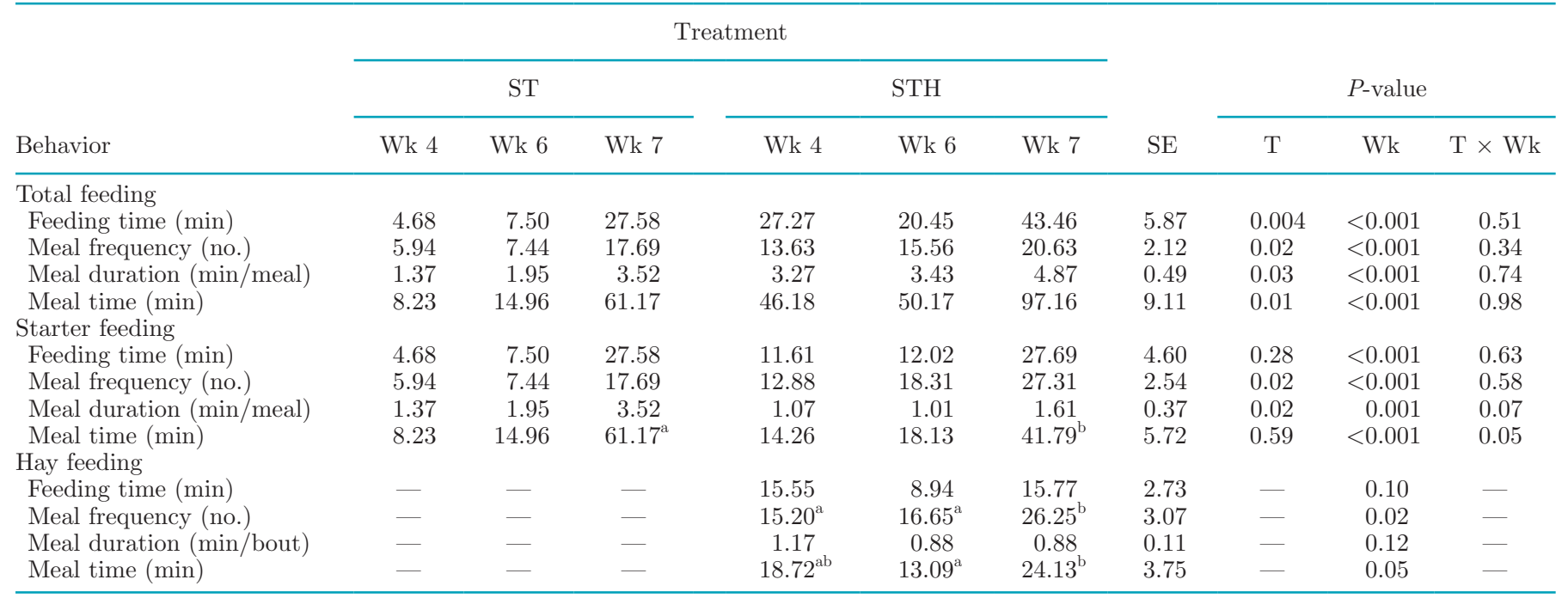

\footnotetext{
${ }^{\mathrm{a}, \mathrm{b}}$ Superscript letters denote a significant within-week treatment effect.
}

${ }^{1}$ All data are summarized and analyzed at the pen level. 

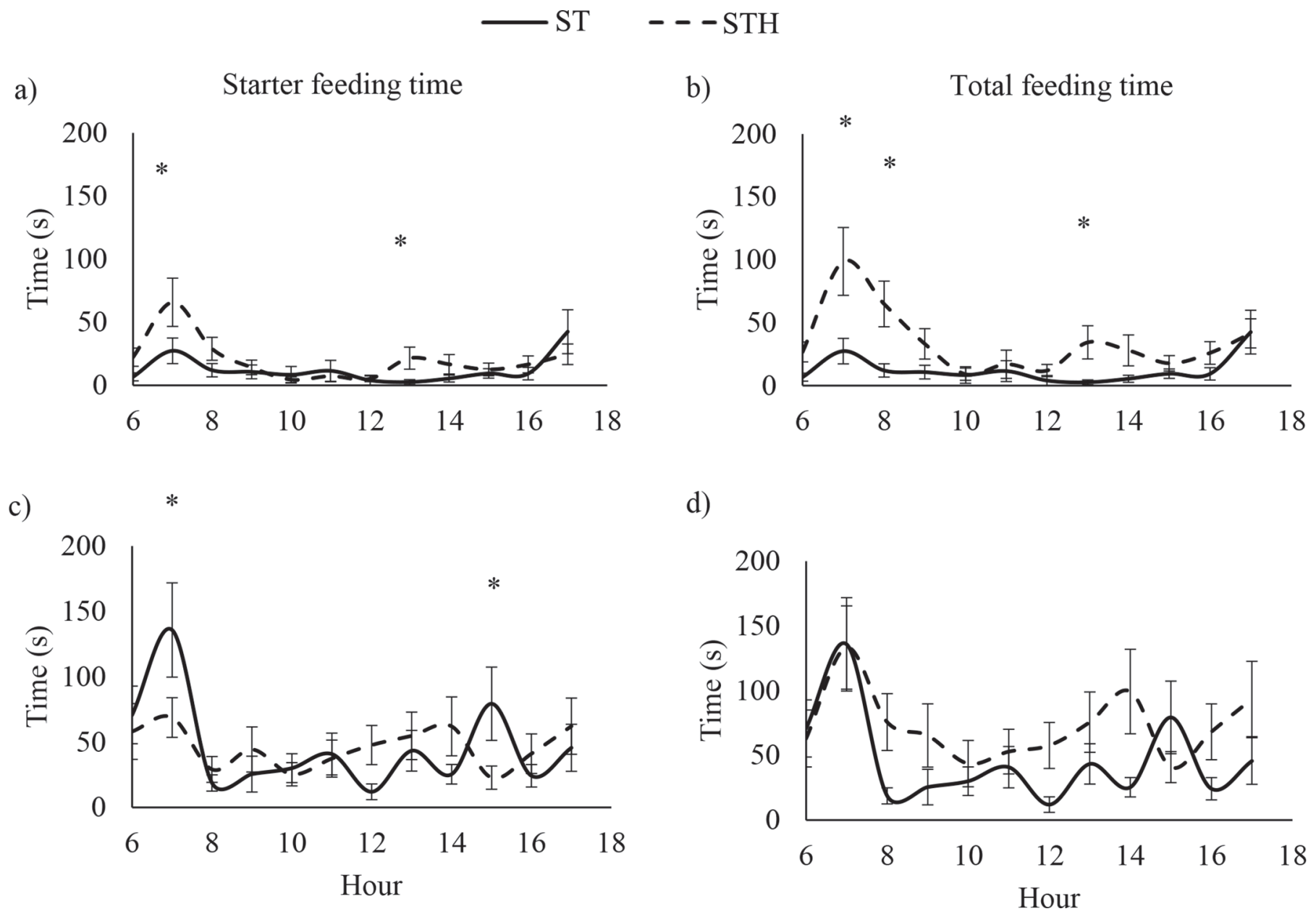

Figure 2. Diurnal feeding patterns of calves offered starter only (ST; $\mathrm{n}=4$ pens) and calves offered both starter and hay (STH; $\mathrm{n}=4$ pens) for (a) total starter feeding time in wk 6 (pre-weaning), (b) total feeding time (including both hay and starter feeding time for STH pens) in wk 6 (pre-weaning), (c) total starter feeding time in wk 7 (weaning), and (d) total feeding time (including both hay and starter feeding time for STH pens) in wk 7 (weaning). Fresh feed was delivered at $0700 \mathrm{~h}$, and pens were cleaned and feed levels were checked at $1300 \mathrm{~h}$. All data are summarized and analyzed at the pen level. Asterisks $\left(^{*}\right)$ indicate significant difference by time point $(P<0.05)$. Error bars indicate SEM at each time point.

starter only did not differ between treatments (no treatment $\times$ hour, $P=0.33$ ). Increased feeding time for STH pens in wk 4 was reflected in diurnal patterns of total time spent feeding (treatment $\times$ hour interaction, $P=0.07$ ), with increased time spent feeding around fresh feed delivery $(0700 \mathrm{~h}$; treatment $\times$ hour, $P=$ 0.004). In wk 6 , the diurnal pattern of starter feeding time was subject to a treatment $\times$ hour interaction $(P$ $=0.02)$, with calves in STH pens spending more time feeding at delivery of fresh feed $(0700 \mathrm{~h} ; P=0.0001)$ and when farm staff was present (for feed top-up and pen cleaning, $1300 \mathrm{~h}, P=0.05$; Figure 2a). The diurnal patterns of total feeding time mirrored differences in starter feeding time $(P=0.003)$, with STH pens having the same greater peaks in time spent consuming all feed $(0700 \mathrm{~h}, P<0.0001 ; 1300 \mathrm{~h}, P=0.02$; Figure 2b). During wk 7, diurnal patterns of starter intake were subject to a treatment $\times$ hour interaction $(P=$ 0.006), with ST pens having a greater peak in feeding time at delivery (0700 h, $P=0.003$; Figure 2c). During weaning (wk 7), there was a tendency for a treatment $\times$ hour interaction $(P=0.096)$, with pens having similar total feeding time at fresh feed delivery, but calves in STH pens spent more time feeding throughout the rest of the day (Figure 2d).

Diurnal patterns of time calves in STH pens spent eating hay compared with starter differed in wk 7 (feed type $\times$ hour interaction, $P=0.04$ ), with calves in these pens spending more time eating hay at time of fresh feed delivery (0700 to $0800 \mathrm{~h}$ ), whereas time spent eating starter was relatively stable across the day (Figure 3). Diurnal feeding activity tended to differ in wk 4 
Table 4. Description of self-grooming and allogrooming behavior and bout characteristics of calves on different treatments (T): provided starter with hay (STH; $\mathrm{n}=4$ pens) or starter only, with no additional feed (ST; $\mathrm{n}=4$ pens), recorded continuously over a 12-h observation period (0600 to $1800 \mathrm{~h}$ ) on 2 consecutive days in wk 4,6 , and 7 of life ${ }^{1}$

\begin{tabular}{|c|c|c|c|c|c|c|c|c|c|c|}
\hline \multirow[b]{2}{*}{ Behavior } & \multicolumn{6}{|c|}{ Treatment } & \multirow[b]{2}{*}{$\mathrm{SE}$} & \multicolumn{3}{|c|}{$P$-value } \\
\hline & Wk 4 & Wk 6 & Wk 7 & Wk 4 & Wk 6 & Wk 7 & & $\mathrm{~T}$ & Wk & $\mathrm{T} \times \mathrm{Wk}$ \\
\hline \multicolumn{11}{|l|}{ Pen-directed sucking } \\
\hline Time (min) & 7.24 & 16.46 & $34.11^{\mathrm{a}}$ & 7.68 & 8.33 & $11.34^{\mathrm{b}}$ & 3.74 & 0.05 & 0.002 & 0.01 \\
\hline Bout frequency (no.) & 11.06 & 18.31 & 27.25 & 11.44 & 14.5 & 17.44 & 4.14 & 0.36 & 0.02 & 0.34 \\
\hline \multicolumn{11}{|l|}{ Self-grooming } \\
\hline Time (min) & 17.71 & 14.47 & $10.68^{\mathrm{a}}$ & 14.35 & 11.66 & $18.77^{\mathrm{b}}$ & 2.14 & 0.78 & 0.24 & 0.02 \\
\hline Bout frequency (no.) & 45.44 & 37.56 & 36.25 & 41.50 & 33.31 & 51.63 & 4.47 & 0.43 & 0.19 & 0.11 \\
\hline Bout duration (s) & 40.34 & 35.73 & 27.11 & 32.03 & 31.06 & 31.73 & 4.02 & 0.47 & 0.38 & 0.35 \\
\hline Bout time (min/bout) & 30.34 & 22.17 & $15.58^{\mathrm{a}}$ & 23.12 & 17.82 & $28.84^{\mathrm{b}}$ & 3.35 & 0.86 & 0.12 & 0.02 \\
\hline \multicolumn{11}{|l|}{ Allogrooming } \\
\hline Time $(\mathrm{s})$ & 138.99 & 191.55 & 204.0 & 230.80 & 153.54 & 276.17 & 77.89 & 0.65 & 0.46 & 0.37 \\
\hline
\end{tabular}

${ }^{\mathrm{a}, \mathrm{b}}$ Superscript letters denote a significant within-week treatment effect.

${ }^{1}$ All data are summarized and analyzed at the pen level.

(feed type $\times$ hour interaction, $P=0.07$ ) with calves spending more time consuming hay at time of delivery. Diurnal patterns of hay and starter feeding time were similar in wk 6 , but calves spent more time consuming hay than starter during this time $(P=0.03)$.

Hay provision reduced the amount of time calves spent performing pen-directed non-nutritive oral behaviors, with calves in ST pens increasing the amount

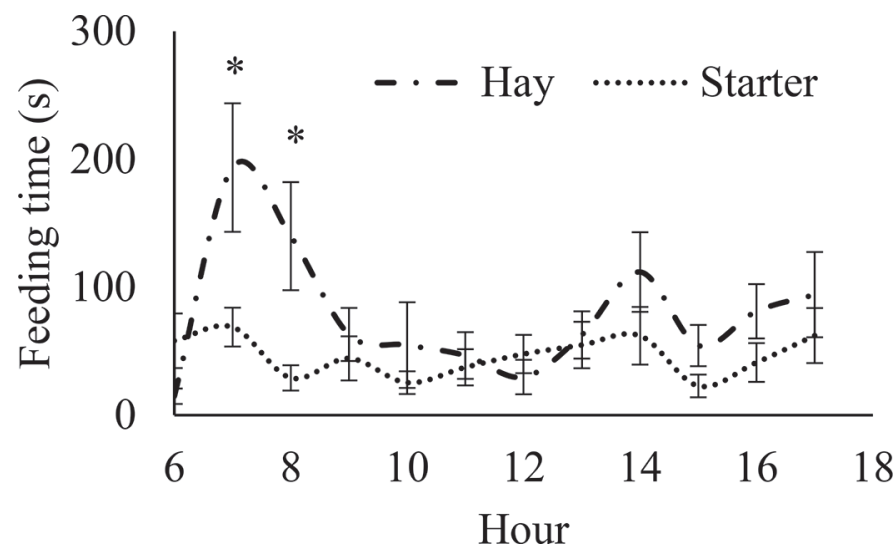

Figure 3. Time (in seconds) spent consuming starter vs. hay by hour for test group STH calves $(\mathrm{n}=4$ pens; $\mathrm{STH}=$ group that was offered both starter and hay) during weaning during wk 7 (weaning). Fresh feed was delivered at $0700 \mathrm{~h}$, and pens were cleaned and feed levels were checked at $1300 \mathrm{~h}$. Data are summarized and analyzed at the pen level. Asterisks ${ }^{*}$ ) indicate significant difference by time point $(P<0.05)$. Error bars indicate SEM at each time point. of time they spent sucking on pen fixtures over time relative to STH (Table 4). Frequency of pen-directed sucking bouts increased across weeks, with no effect of treatment, but the duration of those bouts was greater for calves in ST pens and tended to increase to a greater extent over time. The amount of time spent cross-sucking was similar between treatments (77.04 vs. $90.89 \mathrm{~s} /$ calf per $12 \mathrm{~h}, \mathrm{ST}$ vs. STH pens; $\mathrm{SE}=37.74 ; P$ $=0.80$ ) and evolved similarly over time (treatment $\times$ week, $P=0.41$ ).

Time spent self-grooming evolved differently between treatments, with calves in STH pens increasing and calves in ST pens decreasing the amount of time spent self-grooming during weaning (Table 4). Self-grooming bout frequency and duration was similar across weeks (Table 4). Allogrooming and social lying behaviors were similar between treatments (Table 4).

\section{DISCUSSION}

In this study, we investigated effects of hay provision on behavior and performance of group-housed dairy calves. Forage provision has been well studied in individually housed calves, with performance benefits varying depending on forage variety. In general, providing limited access to forage, either by providing less-palatable forages or by restricting dietary inclusion rate, has been considered optimal to allow for beneficial effects of hay provision without increasing gut fill or reducing starter intake (Castells et al., 2013), which could delay 
rumen development. In the present study, we selected a low-quality hay, aiming to provide the sensory experience of ingesting hay but limit total hay intake during the pre-weaning period. Similar to previous studies conducted with individually housed calves provided lowquality hay or straw (Khan et al., 2011; Castells et al., 2012; Montoro et al., 2013), we found that providing hay to calves did not affect starter intake and therefore resulted in greater total DMI during the pre-weaning stage, particularly during the week before weaning. Interestingly, however, calves in our study selected forage at a higher inclusion rate $(15 \%)$ than is often observed or recommended (e.g., <10\%; Castells et al., 2012, 2013), and a recent meta-analysis has also suggested that high levels of forage ( $>10 \%$ dietary inclusion) are associated with increased starter intake (Imani et al., 2017), suggesting that further evaluation of optimal dietary inclusion of forage may be needed. Aside from effects of forage type, we speculate that the amount of hay selected may depend on milk feeding level; whereas most research in this area has been conducted with calves provided restricted milk allowances (e.g., 10\% of birth weight or 4 to $5 \mathrm{~L} / \mathrm{d}$; Coverdale et al., 2004; Castells et al., 2012, 2013), Khan et al. (2011) provided milk at the same feeding level as the present study (8 L/d) and reported similar levels of hay intake. Similar to the present results, Khan et al. (2011) also reported no effects of hay provision on weight gain during the pre-weaning period or on calf body measurements but did note a tendency for increased ADG during weaning.

In previous work, hay provision also increased total feeding time (Horvath and Miller-Cushon, 2017), similar to the present study. We found that access to hay influenced the pattern of starter feeding behavior, resulting in more frequent, shorter starter meals. This effect may be due to calves with access to hay switching between eating starter and hay. Hay was provided adjacent to starter, and anecdotal observation suggested that calves would switch from one to another at feeding times. In general, patterns of smaller, more frequent meals may be beneficial for the rumen environment, as work in adult cattle indicates that the decline in ruminal $\mathrm{pH}$ following feeding is proportional to meal size (Allen, 1997), and feeding behavior characterized by larger, infrequent meals may increase the risk of subacute ruminal acidosis (Krause and Oetzel, 2006). Further, increased feeding time is associated with secretion of saliva, which acts as a buffer in the rumen (Beauchemin et al., 2008). In young calves, the relationship between solid feed meal patterns and rumen environment has not been well explored. However, some evidence does suggest that meal patterns acquired in early life may persist (Miller-Cushon and DeVries,
2015), such that encouraging a developing pattern of frequent, small meals may be beneficial. Introducing forage early in the pre-weaning stage, as opposed to closer to weaning, has also been found to enhance positive effects associated with forage intake, increasing time spent consuming starter as well as rumination time (Hosseini et al., 2016).

Provision of hay also influenced diurnal patterns of solid feed intake, with differences primarily seen during the hour after feed delivery, when calves provided hay spent relatively more time consuming starter before weaning but less time consuming starter during the week of weaning, compared with calves not provided hay. Similar peaks in feeding time at fresh feed delivery have been reported previously in calves (Miller-Cushon et al., 2013b) and lactating cows (DeVries et al., 2003). We also found that calves provided hay spent more time consuming hay than starter, similar to previous findings (Hepola et al., 2006). These differences in feeding time were primarily due to a much greater peak in hay feeding time than starter feeding time at the time of fresh feed delivery, whereas starter feeding time was relatively stable over the day. Our observed diurnal patterns of hay and starter feeding time are similar to results in weaned calves reported by Miller-Cushon et al. (2013b) as well as findings in goats (Senn et al., 1990). Senn et al. (1990) describe differences between hay and concentrate in correlations of meal size with post-meal interval among goats, suggesting that concentrate intake was primarily regulated by satiety signals, whereas hay intake was stimulated by external stimuli (such as feed delivery). This suggests that the motivational system for hay and starter feeding behavior may be quite different, with hay intake possibly motivated similarly to oral behaviors such as pen-directed sucking, which could explain other behavioral benefits of providing access to hay that we noted in this study.

Interestingly, we found that calves provided hay had fewer unrewarded visits to the milk feeder during weaning. Unrewarded visits have been considered an indicator of hunger in dairy calves on automated milk feeders, with restricted-fed calves having more frequent unrewarded visits than those provided higher milk allowances (de Paula Vieira et al., 2008; Borderas et al., 2009). In the present study, calves not provided hay had almost twice as many unrewarded visits to the automated milk feeder during weaning. Although milk and solid feed intake did not differ between treatments during weaning, hay intake can increase gut fill (Jahn et al., 1970), possibly increasing satiety and explaining less frequent unrewarded visits to the milk feeder. We also observed a tendency for increased ADG during weaning, which may be a result of increased solid feed 
intake during the pre-weaning period, suggesting that calves provided hay experienced a smoother weaning transition. It is also possible that unrewarded visits to the milk feeder may be driven by exploration or boredom, with calves less likely to visit the autofeeder when they are spending more time consuming hay. Overall, these results suggest positive effects of hay on performance and welfare during the critical weaning transition.

Similarly to previous studies of individually housed calves (Haley et al., 1998; Horvath and Miller-Cushon, 2017), hay provision decreased the amount of pendirected sucking in group-housed calves. Additionally, the increase in pen-directed sucking performed by the calves provided starter only was greatest during weaning, which could indicate increased frustration during this period (Margerison et al., 2003), whereas calves provided hay may have redirected this behavior to consuming hay. Although social companions decrease the amount of time spent performing non-nutritive oral behaviors, they also provide opportunity to perform cross-sucking (Pempek et al., 2016). We observed that the duration of cross-sucking occurred similarly to some previous studies; for example, $0.13 \mathrm{~min} / \mathrm{h}$ were spent cross-sucking in the present study, compared with $0.19 \mathrm{~min} / \mathrm{h}$ in group-housed calves (Hepola et al., 2006) and 0.16 min per 30-min observation directed at the head and neck only in socially housed calves (Jensen and Budde, 2006). Contrary to our hypothesis, we did not see an effect of hay provision on cross-sucking, possibly due to the limited amount of time devoted to this behavior across treatments.

Self-grooming is an important maintenance behavior and is subject to physiological and environmental factors. Sickness and disease have been shown to decrease self-grooming in calves (Borderas et al., 2008; Hixson et al., 2018), and certain bedding materials increase self-grooming (Panivivat et al., 2004). Previous studies have found that pre-weaned group-housed calves spend $35 \mathrm{~min} / 11 \mathrm{~h}$ (Hepola et al., 2006) and individually housed calves spend $20 \mathrm{~min} / 8 \mathrm{~h}$ observation period selfgrooming (Horvath and Miller-Cushon, 2017), which is greater than the amount of time we observed calves performing self-grooming $(<18 \mathrm{~min} / 12 \mathrm{~h}$ for both treatments). In our study, we found that calves provided hay spent more time self-grooming during weaning, which, in combination with the increased feeding time and decreased number of unrewarded visits to the automated feeder, suggests that these calves were devoting more of their time to maintenance behaviors instead of behaviors in calves not provided hay that might have been reflective of hunger or boredom. Phillips (2004) also found that offering fresh-cut grass to bucket-fed calves increased self-grooming in group-housed calves but did not see the same effect in individually housed calves. Potential welfare implications of changes in selfgrooming behavior are not currently well understood, and further study of the development of self-grooming behavior in relation to different management changes may shed more light on the importance of this behavior.

Despite effects of hay provision on self-grooming, we found no effect on social behaviors, including allogrooming and social lying, in this study. Allogrooming is used to establish and maintain relationships in a group (Færevik et al., 2007), and we have previously observed an increase in allogrooming in dairy calves upon introduction to a new social group (Horvath and Miller-Cushon, 2018). Although allogrooming was observed for relatively short durations, time spent performing this behavior during our study resembled patterns observed among adult cows (Val-Laillat et al., 2009). Calves in both treatments spent almost half of the 12-h observation period lying next to another calf, which may also help establish social groups, because young calves will routinely lie next to each other when not maternally separated (Sato et al., 1987).

\section{CONCLUSIONS}

Overall, we found positive behavioral and performance effects of hay provision for group-housed calves, particularly approaching and during the weaning transition. Provision of hay increased solid feed intake and overall meal frequency and reduced pen-directed sucking and unrewarded visits to the milk feeder during weaning. Calves provided hay also spent more time self-grooming. These results suggest that providing hay may improve calf welfare, and we encourage further work to evaluate longer-term effects of hay provision on calf behavioral development.

\section{ACKNOWLEDGMENTS}

We thank the staff at the University of Florida Dairy Unit, our laboratory members Catherine Hixson and Kaitlin Gingerich, and our undergraduate research assistants (Rachel Brick, Alexis Brocious, Alyssa Carillo, Tessa Fackler, Mackenzie Holmes, Megan McDowell, Giuliana Pezzella, Taylor Pollak, Sam Stella, and Callie Ward) for their technical assistance. KH was supported by a Matching Assistantship through the Department of Animal Sciences, University of Florida, Gainesville. This study was supported through the Southeast Milk Inc. (Belleview, FL) Milk Check-Off funding program. 


\section{REFERENCES}

Allen, M. S. 1997. Relationship between fermentation acid production in the rumen and the requirement for physically effective fiber. J. Dairy Sci. 80:1447-1462.

AOAC International. 2000. Official Methods of Analysis, Vol. 1. 17th ed. AOAC Int., Arlington, VA.

Beauchemin, K. A., L. Eriksen, P. Nørgaard, and L. M. Rode. 2008. Short Communication: Salivary secretion during meals in lactating dairy cattle. J. Dairy Sci. 91:2077-2081.

Borderas, T. F., A. M. De Passillé, and J. Rushen. 2008. Behavior of dairy calves after a low dose of bacterial endotoxin. J. Anim. Sci. 86:2920-2927.

Borderas, T. F., A. M. B. de Passillé, and J. Rushen. 2009. Feeding behavior of calves fed small or large amounts of milk. J. Dairy Sci. 92:2843-2852.

Castells, L., A. Bach, G. Araujo, C. Montoro, and M. Terré. 2012. Effect of different forage sources on performance and feeding behavior of Holstein calves. J. Dairy Sci. 95:286-293.

Castells, L., A. Bach, A. Aris, and M. Terré. 2013. Effects of forage provision to young calves on rumen fermentation and development of the gastrointestinal tract. J. Dairy Sci. 96:5226-5236.

Costa, J. H. C., N. A. Adderley, D. M. Weary, and M. A. G. von Keyserlingk. 2016. Short communication: Effect of diet changes on sorting behavior of weaned dairy calves. J. Dairy Sci. 99:56355639.

Costa, J. H. C., R. R. Daros, M. A. G. von Keyserlingk, and D. M. Weary. 2014. Complex social housing reduces food neophobia in dairy calves. J. Dairy Sci. 97:7804-7810.

Costa, J. H. C., R. K. Meagher, M. A. G. von Keyserlingk, and D. M. Weary. 2015. Early pair housing increases solid feed intake and weight gains in dairy calves. J. Dairy Sci. 98:6381-6386.

Coverdale, J. A., H. D. Tyler, J. D. Quigley, and J. A. Brumm. 2004. Effect of various levels of forage and form of diet on rumen development and growth in calves. J. Dairy Sci. 87:2554-2562.

de Passillé, A. M. 2001. Sucking motivation and related problems in calves. Appl. Anim. Behav. Sci. 72:175-187.

de Paula Vieira, A., V. Guesdon, A. M. de Passillé, M. A. G. von Keyserlingk, and D. M. Weary. 2008. Behavioural indicators of hunger in dairy calves. Appl. Anim. Behav. Sci. 109:180-189.

DeVries, T. J., M. A. G. Von Keyserlingk, and K. A. Beauchemin. 2003. Short communication: Diurnal feeding pattern of lactating dairy cows. J. Dairy Sci. 86:4079-4082

Færevik, G., I. L. Andersen, M. B. Jensen, and K. E. Bøe. 2007. Increased group size reduces conflicts and strengthens the preference for familiar group mates after regrouping of weaned dairy calves (Bos taurus). Appl. Anim. Behav. Sci. 108:215-228.

Friard, O., and M. Gamba. 2016. BORIS: A free, versatile open-source event-logging software for video/audio coding and live observations. Methods Ecol. Evol. 7:1325-1330.

Galef, B. G., and L. Giraldeau. 2001. Social influences on foraging in vertebrates: Causal mechanisms and adaptive functions. Anim. Behav. 61:3-15.

Haley, D. B., J. Rushen, I. J. Duncan, T. M. Widowski, and A. M. De Passillé. 1998. Effects of resistance to milk flow and the provision of hay on nonnutritive sucking by dairy calves. J. Dairy Sci. 81:2165-2172.

Hepola, H., L. Hänninen, P. Pursiainen, V. M. Tuure, L. Syrjälä-Qvist, M. Pyykkönen, and H. Saloniemi. 2006. Feed intake and oral behaviour of dairy calves housed individually or in groups in warm or cold buildings. Livest. Sci. 105:94-104.

Hixson, C. L., P. D. Krawczel, J. M. Caldwell, and E. K. Miller-Cushon. 2018. Behavioral changes in group-housed dairy calves infected with Mannheimia haemolytica. J. Dairy Sci. 101:10351-10360.

Horvath, K. C., and E. K. Miller-Cushon. 2017. The effect of milkfeeding method and hay provision on the development of feeding behavior and non-nutritive oral behavior of dairy calves. J. Dairy Sci. 100:3949-3957.

Horvath, K. C., and E. K. Miller-Cushon. 2018. Characterizing social behavior, activity, and associations between cognition and be- havior upon social grouping of weaned dairy calves. J. Dairy Sci. 101:7287-7296.

Horvath, K. C., and E. K. Miller-Cushon. 2019. Characterizing grooming behavior patterns and the influence of brush access on the behavior of group-housed dairy calves. J. Dairy Sci. 102:3421-3430.

Hosseini, S. M., G. R. Ghorbani, P. Rezamand, and M. Khorvash. 2016. Determining optimum age of Holstein dairy calves when adding chopped alfalfa hay to meal starter diets based on measures of growth and performance. Animal 10:607-615.

Imani, M., M. Mirzae, B. Baghbanzadeh-Nobari, and M. H. Ghaffari. 2017. Effects of forage provision to dairy calves on growth performance and rumen fermentation: A meta-analysis and metaregression. J. Dairy Sci. 100:1136-1150.

Jahn, E., P. T. Chandler, and C. E. Polan. 1970. Effects of fiber and ratio of starch to sugar on performance of ruminating calves. J. Dairy Sci. 53:466-474.

Jensen, M. B., and M. Budde. 2006. The effects of milk feeding method and group size on feeding behavior and cross-sucking in grouphoused dairy calves. J. Dairy Sci. 89:4778-4783.

Jensen, M. B., and D. Weary. 2013. Group housing and milk feeding of dairy calves. WCDS Advances in Dairy Technology. 25:179-189.

Jung, J., and L. Lidfors. 2001. Effects of amount of milk, milk flow and access to a rubber teat on cross-sucking and non-nutritive sucking in dairy calves. Appl. Anim. Behav. Sci. 72:201-213.

Khan, M. A., D. M. Weary, and M. A. G. von Keyserlingk. 2011. Hay intake improves performance and rumen development of calves fed higher quantities of milk. J. Dairy Sci. 94:3547-3553.

Krause, K. M., and G. R. Oetzel. 2006. Understanding and preventing subacute ruminal acidosis in dairy herds: A review. Anim. Feed Sci. Technol. 126:215-236.

Lidfors, L. M. 1993. Cross-sucking in group-housed dairy calves before and after weaning off milk. Appl. Anim. Behav. Sci. 38:15-24.

Lupoli, B., B. Johansson, K. Uvnäs-Moberg, and K. SvennerstenSjaunja. 2001. Effect of suckling on the release of oxytocin, prolactin, cortisol, gastrin, cholecystokinin, somatostatin and insulin in dairy cows and their calves. J. Dairy Res. 68:175-187.

Macdonald, P., and J. Du. 2018. mixdist: Finite Mixture Distribution Models. $\mathrm{R}$ package version 0.5-5. Accessed Jan. 15, 2019. https:// CRAN.R-project.org $/$ package $=$ mixdist

Margerison, J. K., T. R. Preston, N. Berry, and C. J. C. Phillips. 2003. Cross-sucking and other oral behaviours in calves, and their relation to cow suckling and food provision. Appl. Anim. Behav. Sci. $80: 277-286$

Miller-Cushon, E. K., R. Bergeron, K. E. Leslie, G. J. Mason, and T. J. DeVries. 2013a. Effect of early exposure to mixed rations differing in forage particle size on feed sorting of dairy calves. J. Dairy Sci. 96:3257-3264.

Miller-Cushon, E. K., R. Bergeron, K. E. Leslie, G. J. Mason, and T. J. DeVries. 2013b. Effect of feed presentation on feeding patterns of dairy calves. J. Dairy Sci. 96:7260-7268.

Miller-Cushon, E. K., and T. J. DeVries. 2015. Invited Review: Development and expression of dairy calf feeding behaviour. Can. J. Anim. Sci. 95:341-350.

Miller-Cushon, E. K., and T. J. DeVries. 2016. Effect of social housing on the development of feeding behavior and social feeding preferences of dairy calves. J. Dairy Sci. 99:1406-1417.

Montoro, C., E. K. Miller-Cushon, T. J. DeVries, and A. Bach. 2013. Effect of physical form of forage on performance, feeding behavior, and digestibility of Holstein calves. J. Dairy Sci. 96:1117-1124.

Nicol, A. M., and M. A. Sharafeldin. 1975. Observations on the behaviour of single-suckled calves from birth to 120 days. Proc. N.Z. Soc. Anim. Prod. 35:221-230.

Panivivat, R., E. B. Kegley, J. A. Pennington, D. W. Kellogg, and S. L. Krumpelman. 2004. Growth performance and health of dairy calves bedded with different types of materials. J. Dairy Sci. $87: 3736-3745$.

Pazoki, A., G. R. Ghorbani, S. Kargar, A. Sadeghi-Sefidmazgi, J. K. Drackley, and M. H. Ghaffari. 2017. Growth performance, nutrient digestibility, ruminal fermentation, and rumen development of calves during transition from liquid to solid feed: Effects of 
physical form of starter feed and forage provision. Anim. Feed Sci. Technol. 234:173-185.

Pempek, J. A., M. L. Eastridge, S. S. Swartzwelder, K. M. Daniels, and T. T. Yohe. 2016. Housing system may affect behavior and growth performance of Jersey heifer calves. J. Dairy Sci. 99:569-578.

Phillips, C. J. C. 2004. The effects of forage provision and group size on the behavior of calves. J. Dairy Sci. 87:1380-1388.

Sato, S., D. G. M. Wood-Gush, and G. Wetherill. 1987. Observations on creche behaviour in suckler calves. Behav. Processes 15:333-343.

Senn, M., W. Langhans, and E. Scharrer. 1990. Meal patterns of pygmy goats fed hay and concentrate ad lib. Physiol. Behav. 48:49-53.

Simonsen, H. B. 1994. Skin stimulated induction of mouth movements in cattle. Anim. Welf. 3:129-134.

Suarez-Mena, F. X., T. M. Hill, C. M. Jones, and A. J. Heinrichs. 2016. Review: Effect of forage provision on feed intake in dairy calves. Prof. Anim. Sci. 32:383-388.

Ueno, R. K., M. Neumann, F. Marafon, M. Ambrogi, B. A. Daros, and E. Pletz. 2014. Effect of hay on performance of Holstein calves at suckling and post-weaning. Rev. Ceres 61:668-674.
Val-Laillat, D., V. Guesdon, M. A. G. von Keyserlingk, A. M. de Passille, and J. Rushen. 2009. Allogrooming in cattle: Relationships between social preferences, feeding displacements and social dominance. Appl. Anim. Behav. Sci. 116:141-149.

Van Soest, P. J., J. B. Robertson, and B. A. Lewis. 1991. Methods for dietary fiber, neutral detergent fiber, and nonstarch polysaccharides in relation to animal nutrition. J. Dairy Sci. 74:3583-3597.

Webb, L. E., B. Engel, H. Berends, C. G. van Reenen, W. J. J. Gerrits, I. J. M. de Boer, and E. A. M. Bokkers. 2014. What do calves choose to eat and how do preferences affect behavior? Appl. Anim. Behav. Sci. 161:7-19.

Webb, L. E., C. G. van Reenen, H. Berends, B. Engel, I. J. M. de Boer, W. J. J. Gerrits, and E. A. M. Bokkers. 2015. The role of solid feed amount and composition and of milk replacer supply in veal calf welfare. J. Dairy Sci. 98:5467-5481. 